\title{
Renal cell carcinoma: standards and controversies
}

\author{
Tobias Klatte ${ }^{1,2} \cdot$ Grant D. Stewart $^{2,3}$
}

Published online: 12 September 2018

c) Springer-Verlag GmbH Germany, part of Springer Nature 2018

The purpose of this topic issue of the World Journal of Urology is to relay novel developments and controversies in renal cell carcinoma (RCC). To achieve this, we have selected renowned experts to review various scientific and clinical aspects of RCC. The pace of basic, translational and clinical RCC research development is rapid. We have selected, as outlined below, those topics where we felt that we must improve our knowledge and understanding to provide improved prevention, diagnostic and treatment strategies to our patients.

With the widespread use of modern cross-sectional abdominal imaging, the incidence of asymptomatic renal tumours has been increasing, especially in patients over the age of $70[1,2]$. Many of these incidentalomas do not have and will not develop adverse pathological or clinical features meaning any intervention may not change the natural history of the disease. Unfortunately, while imaging is an essential part of the workup, precise criteria to determine the biology of a renal tumour are lacking [2]. However, this "opportunistic", unspecific screening by non-urological specialities has decreased the number of patients presenting with advanced RCC [1], which results from a shift to an earlier stage where $\mathrm{RCC}$ is curable or does not cause harm if left alone. "Smart" ultrasound-based screening of a target population defined by established risk factors (age, sex, body mass index, smoking history) and promising plasma markers such as kidney injury molecule-1 [3] may be even more beneficial. Such a strategy may increase the incidence of the disease but would hopefully further decrease mortality rates. If we utilise renal tumour biopsy and active surveillance wisely, intervention

Tobias Klatte

tobias.klatte@gmx.de; tobias.klatte@ rbch.nhs.uk

1 Department of Urology, Royal Bournemouth and Christchurch Hospitals NHS Foundation Trust, Bournemouth, UK

2 Academic Urology Group, Department of Surgery, University of Cambridge, Cambridge, UK

3 Department of Urology, Addenbrooke's Hospital, Cambridge University Hospitals NHS Foundation Trust, Cambridge, UK rates will remain on a similar level. Overtreatment of screendetected tumours must be avoided at all costs.

Research into the biology and the genetic basis of RCC has led to a greater understanding of molecular pathways, refinements in pathological classification, development of drugs and new prognostic factors. The trunk-branch model of key genetic events and heterogeneity is now generally accepted, with many of these events occurring years to decades before tumours become clinically evident [4]. Many more landmark studies will be published from the TRACERx Renal Consortium and other initiatives in the foreseeable future. The review article in this topic issue includes a summary of recent evidence, but also a methodological overview and a glossary of terms used to describe genetic changes [4]. We hope that this will serve as a comprehensive up-to-date resource for urologists, specifically for those not involved in genomic research. Similarly, the review on the most recent WHO classification, staging and grading of renal tumours by Warren and Harrison [5] outlines standards and controversies from the perspective of pathologists. It remains important to look beyond our own immediate specialty to provide high-quality care.

Despite several efforts with adjuvant phase III trials in high-risk non-metastatic RCC, a clinically significant survival benefit has not yet been demonstrated and postoperative follow-up imaging remains the standard of care. Despite its importance in clinical practice, there is little high-quality evidence in this field. RECUR is a multicentre consortium which established collaborative research studies regarding postoperative follow-up, and the lead investigators of this group provided a comprehensive review for this topic issue [6]. It is worth noting that the established followup guidelines differ regarding frequency, type of imaging and prognostic stratification, and do not consider competing risks such as age and comorbidity [6-8]. Furthermore, there is little data regarding health-related quality of life outcomes after surgery [9]. Clearly, high-quality evidencebased follow-up protocols are a research priority, but will rely on accurate prognostic stratification at baseline. This topic issue contains a literature review on prognostic factors 
and models, all of which have limited accuracy. Molecular markers can improve the accuracy of these models, but frequently lack external, independent validation [10]. Validation of molecular markers is another research priority, as one can regard only validated markers as biomarkers.

Another controversy is the use of cytoreductive nephrectomy in patients with synchronous metastatic RCC. The CARMENA trial showed that sunitinib alone is not inferior to cytoreductive nephrectomy and sunitinib for both intermediate- and high-risk metastatic clear-cell RCC, which constitute more than $95 \%$ of newly diagnosed patients with metastatic disease [11]. Despite level I evidence, CARMENA had several limitations, and it is still thought that cytoreductive nephrectomy can prolong survival in select patients [12]. In particular, studies show that patients in a good performance status, with low metastatic burden and a predicted survival of over 12 months will most likely benefit from surgery [13, 14]. The preoperative MD Anderson nomogram is based on serum levels of albumin and lactate dehydrogenase and can estimate 6-month survival outcomes after cytoreductive nephrectomy [15]. In this issue, Marconi et al. [16] validated this nomogram in an independent cohort of 1100 patients and confirmed its accuracy and calibration. Importantly, both albumin and lactate dehydrogenase are not included in the most recent MSKCC and Heng prognostic models [10], which may therefore be less accurate in selecting patients for surgery than the nomogram.

We hope you will enjoy reading those papers as much as we did while preparing this topic issue.

\section{References}

1. Rossi SH, Klatte T, Usher-Smith J, Stewart GD (2018) Epidemiology and screening for renal cancer. World J Urol 36:1341-1353. https://doi.org/10.1007/s00345-018-2286-7

2. Rossi SH, Prezzi D, Kelly-Morland C, Goh V (2018) Imaging for the diagnosis and response assessment of renal tumours. World $\mathrm{J}$ Urol. https://doi.org/10.1007/s00345-018-2342-3

3. Scelo G, Muller DC, Riboli E et al (2018) KIM-1 as a blood-based marker for early detection of kidney cancer: a prospective nested case-control study. Clin Cancer Res. https://doi.org/10.1158/10780432.CCR-18-1496

4. Mitchell TJ, Rossi SH, Klatte T, Stewart GD (2018) Genomics and clinical correlates of renal cell carcinoma. World J Urol. https:// doi.org/10.1007/s00345-018-2429-x

5. Warren AY, Harrison D (2018) WHO/ISUP classification, grading and pathological staging of renal cell carcinoma: standards and controversies. World J Urol. https://doi.org/10.1007/s0034 5-018-2447-8

6. Dabestani S, Marconi L, Kuusk T, Bex A (2018) Follow-up after curative treatment of localised renal cell carcinoma. World J Urol. https://doi.org/10.1007/s00345-018-2338-z

7. Beisland C, Guðbrandsdottir G, Reisæter LAR et al (2016) A prospective risk-stratified follow-up programme for radically treated renal cell carcinoma patients: evaluation after eight years of clinical use. World J Urol 34:1087-1099

8. Kuijpers YA, Meijer RP, Jonges GN et al (2016) Potentially curable recurrent disease after surgically managed non-metastatic renal cell carcinoma in low-, intermediate- and high-risk patients. World J Urol 34:1073-1079

9. Rossi SH, Klatte T, Stewart GD (2018) Quality of life outcomes in patients with localised renal cancer: a literature review. World J Urol. https://doi.org/10.1007/s00345-018-2415-3

10. Klatte T, Rossi SH, Stewart GD (2018) Prognostic factors and prognostic models for renal cell carcinoma: a literature review. World J Urol. https://doi.org/10.1007/s00345-018-2309-4

11. Méjean A, Ravaud A, Thezenas S et al (2018) Sunitinib alone or after nephrectomy in metastatic renal-cell carcinoma. $\mathrm{N}$ Engl $\mathrm{J}$ Med 379:417-427

12. Motzer RJ, Russo P (2018) Cytoreductive nephrectomy-patient selection is key. N Engl J Med 379:481-482

13. Faba OR, Brookman-May SD, Linares E et al (2017) Cytoreductive nephrectomy in patients with metastatic renal cell carcinoma in the era of targeted therapy: a bibliographic review. World J Urol 35:1807-1816

14. Klatte T, Fife K, Welsh SJ et al (2018) Prognostic effect of cytoreductive nephrectomy in synchronous metastatic renal cell carcinoma: a comparative study using inverse probability of treatment weighting. World J Urol 36:417-425

15. Margulis V, Shariat SF, Rapoport Y et al (2013) Development of accurate models for individualized prediction of survival after cytoreductive nephrectomy for metastatic renal cell carcinoma. Eur Urol 63:947-952

16. Marconi L, de Bruijn R, van Werkhoven E et al (2018) External validation of a predictive model of survival after cytoreductive nephrectomy for metastatic renal cell carcinoma. World J Urol. https://doi.org/10.1007/s00345-018-2427-z 